\title{
Situasi Tuberkulosis di Empat Kabupaten/Kota di Pulau Sumatera dan Banten
}

\section{Tuberculosis Situation in Four Districts in Sumatera Island and Banten}

\author{
Ajeng Tias Endarti ${ }^{1,2^{*}}$, Izza Suraya ${ }^{1,3}$, Muttaqien $^{4}$, Adelia Ulya Rachman ${ }^{4}$, \\ Rizki Tsalatshita Khair $\mathbf{M}^{4}$ \\ ${ }^{1}$ Ikatan Ahli Kesehatan Masyarakat Indonesia (IAKMI) \\ ${ }^{2}$ Universitas MH Thamrin Jakarta \\ ${ }^{3}$ Universitas Prof. Dr. HAMKA Jakarta \\ ${ }^{4}$ Pusat Kebijakan Pembiayaan dan Manajemen Asuransi Kesehatan Fakultas Kedokteran \\ Universitas Gadjah Mada (Pusat KPMAK FK UGM) \\ (*ajengtias@thamrin.ac.id)
}

\begin{abstract}
ABSTRAK
Analisis situasi TB dan biaya program TB pada tingkat kabupaten/kota belum banyak dilakukan padahal hal ini sangat penting untuk perencanaan, penganggaran, pembiayaan dan evaluasi pelayanan TB. Studi dilakukan di Kabupaten Tangerang, Kabupaten Tanggamus, Kota Metro dan Kota Dumai dengan pendekatan mixed method. Pengumpulan data kuantitatif menggunakan data sekunder untuk mengetahui situasi dan biaya program TB. Pengumpulan data primer dilakukan secara kualitatif dengan melakukan round table discussion dengan para stakeholder. Hasil studi menunjukkan insiden TB dan success rate tertinggi di Kabupaten Tanggamus. Kota Metro juga memiliki insiden TB tertinggi disertai dengan notifikasi kasus tertinggi. Kabupaten Tangerang memiliki cure rate tertinggi. Biaya program TB tertinggi di Kabupaten Tangerang, yaitu Rp. 6.737.303.630,-. Alokasi biaya program TB terbesar di semua wilayah digunakan untuk obat. Permasalahan yang terjadi dalam pengendalian TB di empat wilayah tersebut adalah tatalaksana kasus tidak standar, underestimated data, temuan kasus baru masih kurang, terbatasnya SDM program TB, kontribusi CSR sangat rendah, kurangnya upaya promotif dan preventif tentang TB, stigma buruk TB, kesulitan monitoring dan evaluasi kasus dan survei kontak, dan permasalahan pasien dari kelompok miskin dan kelompok pekerja. Pengendalian TB di semua wilayah belum optimal maka direkomendasikan untuk segera membuat payung hukum untuk memberikan kekuatan anggaran dan kerjasama lintas sektor dalam pengendalian TB.
\end{abstract}

Kata kunci : Tuberkulosis, analisis situasi, beban TB, insiden TB

\section{ABSTRACT}

Situational and costing analysis of TB burden in district level is rarely conducted eventhough its importances in planning, budgeting, costing and evaluating TB care services. Study conducted in Tangerang District, Tanggamus District, Metro City and Dumai City with mixed method approach. Quantitative data collection used secondary data to current situation and cost of TB programme. Meanwhile qualitative data collection through round table discussion with stakeholders. TB incidence and success rate of medication were highest in Tanggamus District. Metro City had the highest incidence and cure rate. The highest TB costing were allocated in Tangerang District, Rp. 6.737.303.630,-. Within all regions, costing washighly allocated for drug. Problems in TB control were unstandardized TB care, underestimated data, lack of case finding, limited man power for TB programme, lack of CSR contribution, lack of promotive and preventive activity, bad stigma, difficulty in monitoring and evaluation and cantack survey, and specific issues among low income and worker population. TB control among these four regions were not optimized, the we recommend to developing the policy in district level as an umbrella to strengthen the budget and cross-sectoralcollaboration.

Keywords : Tuberculosis, situation analysis, TB burden, TB incidence 


\section{PENDAHULUAN}

Laporan Tuberkulosis Global tahun $2017^{1}$ melaporkan bahwa pada tahun 2016 tuberkulosis (TB) berada pada urutan kesembilan untuk penyebab kematian terbanyak di dunia, yaitu sekitar 2 juta kematian. Sebanyak 10,4 juta orang $(90 \%$ dewasa, $65 \%$ laki-laki dan $10 \%$ penderita HIV) menderita TB pada tahun yang sama. Distribusi kasus TB ini paling banyak terjadi di Asia Tenggara $(45 \%)$ dan Indonesia menempati urutan kedua kasus TB terbanyak setelah India.

Walaupun permasalahan TB di Indonesia masih cukup tinggi, tetapi tren prevalensi TB dalam 23 tahun terakhir telah menunjukkan penurunan sekitar 50\%. Pada tahun 1990 prevalensi TB sebesar 443 kasus per 100.000 penduduk. Angka ini turun menjadi 257 kasus per 100.000 penduduk pada tahun 2013. ${ }^{2}$ Temuan kasus TB yang diukur dengan Case Notification Rate (CNR) sejak tahun 2005 hingga 2015 cukup fluktuatif dan pada tahun 2015 mencapai 125 kasus TB per 100.000 penduduk. Angka tersebut menunjukkan bahwa belum semua kasus TB di populasi dapat ditemukan untuk mendapatkan pengobatan.

World Health Organization ${ }^{1}$ melaporkan bahwa insiden TB di Indonesia pada tahun 2016 sebanyak 1.020.000 kasus (660.000-1.460.000) dengan angka kematian mencapai 110.000 jiwa (75.000-152.000) yang menyebabkan kerugian ekonomi akibat TB cukup besar. Berdasarkan penelitian yang dilakukan oleh Collins, et al., ${ }^{3}$ peningkatan jumlah kasus yang diobati berdampak besar pada beban ekonomi di suatu daerah. Pada penelitian tersebut dicontohkan satu kasus pada tahun 2011 angka TB yang diobati sebesar 72,7\% apabila angka tersebut meningkat menjadi $92,7 \%$ maka beban ekonomi akan berkurang dari 2 miliar USD menjadi 1,3 miliar USD.

Selain dampak ekonomi tersebut, upaya pengendalian TB juga memerlukan biaya yang cukup besar. Hasil modeling proyeksi biaya nasional untuk memberikan layanan pengendalian TB pada 2013 adalah sebesar 57 juta USD $(\$ 0,24$ sen per kapita per tahun) dengan biaya satuan kasus TB adalah 158 USD, sedangkan TB resisten obat mencapai 5.437 USD. Beban biaya tersebut tentunya akan berbeda untuk setiap daerah. Studi yang dilakukan oleh Setiawan pada tahun 2016 menunjukkan bahwa biaya program TB di Kabu- paten Garut sebesar Rp. 2,5 miliar sedangkan biaya program di Kota Cirebon, hanya sebesar Rp. 1,5 miliar. $^{4}$

Besarnya anggaran pengendalian tersebut membuat Indonesia memerlukan bantuan (hibah) dari pihak lain. Sejalan dengan program AIDS, TB dan Malaria (ATM), program TB memiliki ketergantungan terhadap donor dari Global Fund. Oleh karena itu, kedepannya pendanaan dan anggaran lokal bagi program kesehatan akan semakin besar. Pada tahun 2016 anggaran pemerintah untuk ATM ditargetkan mencapai $80 \%$ dan $20 \%$ sisanya bersumber dari dana Corporate Social Responsibility (CSR) dan jaminan kesehatan melalui Sistem Jaminan Sosial Nasional (SJSN) sebagai sumber pendanaan lain yang dianggap lebih memadai. ${ }^{5}$

Untuk mencapai target program Penanggulangan TB nasional, Pemerintah Daerah provinsi dan Pemerintah Daerah kabupaten/kota harus menetapkan target penanggulangan TB tingkat daerah berdasarkan target nasional dan memperhatikan strategi nasional. ${ }^{6}$ Sesuai dengan Peraturan Menteri Kesehatan Republik Indonesia Nomor 67 Tahun 2016 tentang Penanggulangan Tuberkulosis, strategi pengendalian TB di Indonesia adalah 1) penguatan kepemimpinan program $T B, 2$ ) peningkatan akses layanan TB yang bermutu, 3) pengendalian faktor risiko $\mathrm{TB}, 4)$ peningkatan kemitraan $\mathrm{TB}, 5)$ peningkatan kemandirian masyarakat dalam penanggulangan $\mathrm{TB}$, dan 6) penguatan manajemen program TB.

Kebijakan yang telah ditetapkan tetap membutuhkan dukungan fasilitas kesehatan yang lengkap, meliputi ketersediaan puskesmas, klinik, dan rumah sakit, alat-alat medis, dan bahan baku medis. Selain fasilitas kesehatan, tenaga kerja yang profesional dan memadai akan mendukung keberlangsungan pelayanan kesehatan bagi penduduk yang bersangkutan. Dukungan yang telah dipaparkan tersebut merupakan dukungan fisik yang juga membutuhkan dukungan materi berupa ketersediaan dana untuk anggaran rumah sakit, klinik, puskesmas, serta tenaga kerja kesehatan.

Penelitian bertujuan mengetahui situasi TB di empat kabupaten/kota di Pulau Sumatera dan Banten. Situasi TB yang diamati terdiri dari angka temuan kasus, success rate, cure rate, biaya program TB dan alokasinya, serta permasalahan 
yang dihadapi dalam pengendalian TB di wilayah pengamatan. Terkait dengan biaya program TB, berdasarkan hasil telaah literatur, studi terkait dengan hal tersebut pada tingkat kabupaten/kota sangat jarang dilakukan. Hingga saat ini baru ditemukan satu studi tentang pembiayaan program TB di Kabupaten Garut dan Kota Cirebon. ${ }^{4}$ Oleh karena itu, studi ini penting dilakukan untuk mengestimasi biaya pengendalian TB di masing-masing wilayah studi yang sangat diperlukan untuk perencanaan, penganggaran, pembiayaan dan evaluasi pelayanan $\mathrm{TB} .^{7}$

\section{BAHAN DAN METODE}

Penelitian dilakukan dengan pendekatan campuran (mixed method) dengan model sequencial explanatory. Dengan pendekatan ini maka prosedur pengumpulan data pertama kali dilakukan secara kuantitatif untuk mengeksplorasi penyakit dan program $\mathrm{TB}$, kemudian temuan ini digali lebih dalam dengan menggunakan studi kualitatif. Penelitian dilakukan di empat kabupaten/kota, yaitu Kabupaten Tangerang Provinsi Banten, Kabupaten Tanggamus dan Kota Metro Provinsi Lampung dan Kota Dumai Provinsi Riau pada bulan Agustus-September 2017. Alasan pemilihan keempat lokasi ini adalah adanya program TB-HIV pada komunitas yang dijalankan oleh Aisyiah. Selain itu, keempat wilayah ini juga merupakan bagian dari 82 kabupaten/kota lainnya di seluruh Indonesia yang masuk ke dalam projek analisis situasi TB di Indonesia tahun 2017 yang dibiayai oleh Global Fund.

Pengumpulan data sekunder dilakukan dengan menggunakan data profil kesehatan, Sistem Informasi Tuberkulosis Terpadu (SITT) TB dan laporan rutin Dinas Kesehatan. Data tersebut kemudian digunakan untuk menghitung beban biaya TB dan beban ekonomi TB. Pengisian tools dilakukan secara bersama-sama oleh peneliti dan wasor/petugas TB di daerah pada suatu kegiatan workshopbersama selama dua hari. Tools penghitungan biaya dan beban ekonomi TB dikembangkan oleh Pusat KPMAK FK UGM. Data primer dikumpulan melalui studi kualitatif dengan melakukan Round Table Discussion (RTD) dengan stakeholder terkait pengendalian TB yaitu Bidang P2M Dinas Kesehatan. Bapeda, BPJS, DPKAD, Dinas Tanaga Kerja, Penanggung Jawab Program TB di Puskesmas, DPM dan LSM TB Aisyiah. Analisis data sekunder dilakukan secara deskriptif dan disajikan dalam bentuk tabel dan grafik. Penghitungan pembiayaan dan beban ekonomi TB menggunakan software Ms. Excel yang telah dikembangkan oleh Pusat KP-MAK Fakultas Kedokteran UGM. Analisis data primer dilakukan bersifat induktif atau kualitatif berdasarkan fakta-fakta yang ditemukan di lapangan.

\section{HASIL}

Studi dilakukan pada empat kabupaten dan kota yang memiliki karakteristik yang bervariasi. Dua lokasi studi adalah kabupaten yang terdiri dari lebih dari 20 kecamatan, sedangkan dua wilayah lainnya adalah kota dengan sekitar 5-9 kecamatan. Diantara wilayah tersebut, Kabupaten Tangerang adalah wilayah yang paling besar dengan $29 \mathrm{keca}-$ matan dan wilayah yang paling kecil adalah Kota Metro (5 kecamatan). Dengan semakin, besar wilayah kabupaten/kota, jumlah penduduk yang berada di dalamnya pun akan semakin banyak, seperti di Kabupaten Tangerang yang memiliki penduduk sebanyak 3.370.594 orang dengan rasio jumlah laki-laki dengan perempuan 1,05, dan Kota Metro memiliki penduduk 158.415 jiwa (rasio 1,00). Gambaran wilayah kabupaten/kota dalam penelitian ini disajikan dalam Tabel 1.

Insiden TB di dua kabupaten/kota di Provin-

Tabel 1. Karakteristik Wilayah Penelitian

\begin{tabular}{lcccc}
\hline & Kabupaten Tangerang & Kabupaten Tanggamus & Kota Metro & Kota Dumai \\
\hline Jenis Kelamin & & & & \\
$\quad$ Laki-laki & $1,724,915$ & 299,214 & 79,191 & 146,792 \\
Perempuan & $1,645,679$ & 274,690 & 79,224 & 139,175 \\
Rasio & 1,05 & 1,09 & 1,00 & 1,05 \\
Total & $3,370,594$ & 573,904 & 158,415 & 285,967 \\
Jumlah Kecamatan & 29 & 20 & 5 & 7 \\
\hline
\end{tabular}

Sumber : Data Sekuner, 2016 


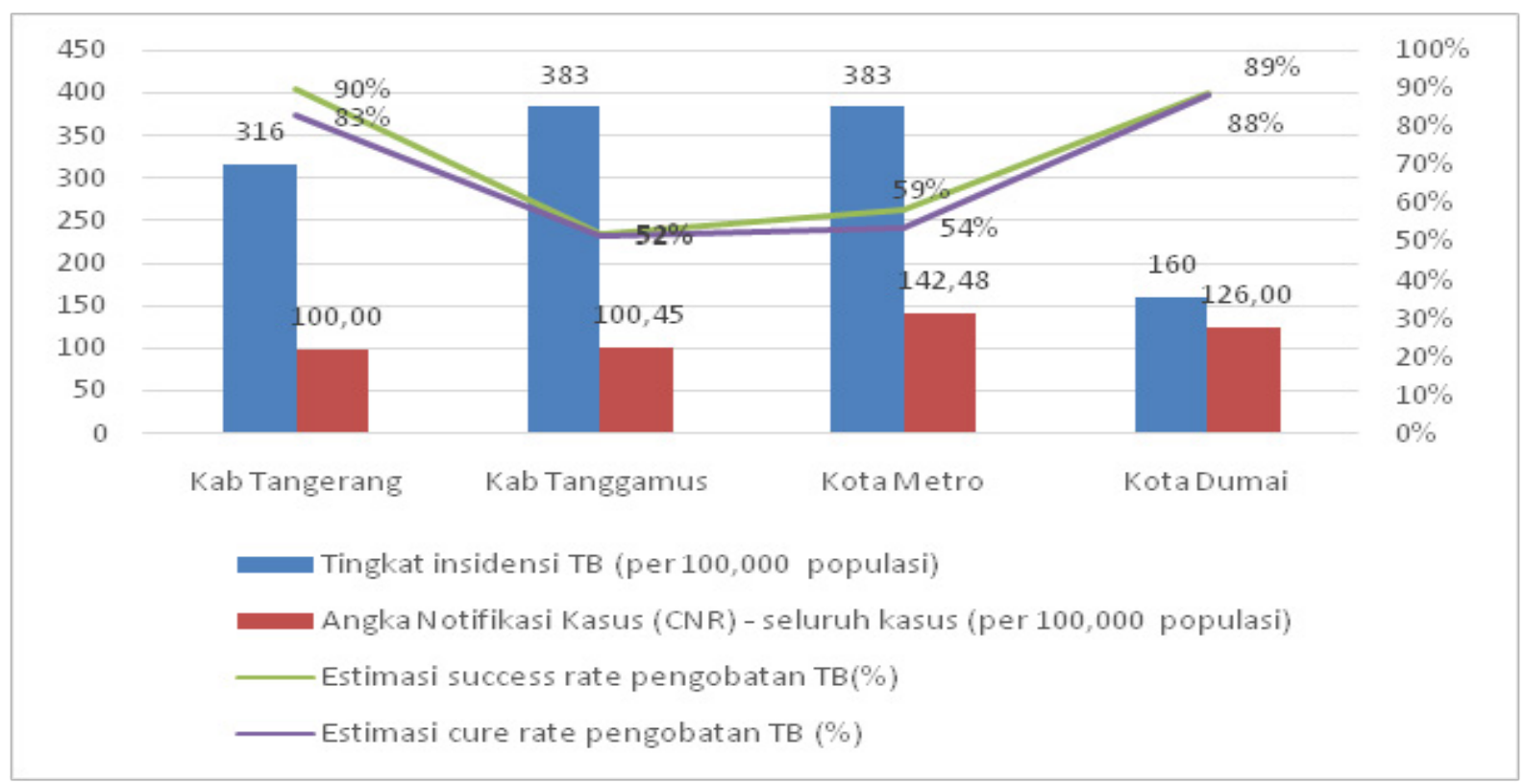

Gambar 1. Gambaran Situasi TB di 4 Kabupaten Kota di Sumatera dan Banten Tahun 2016

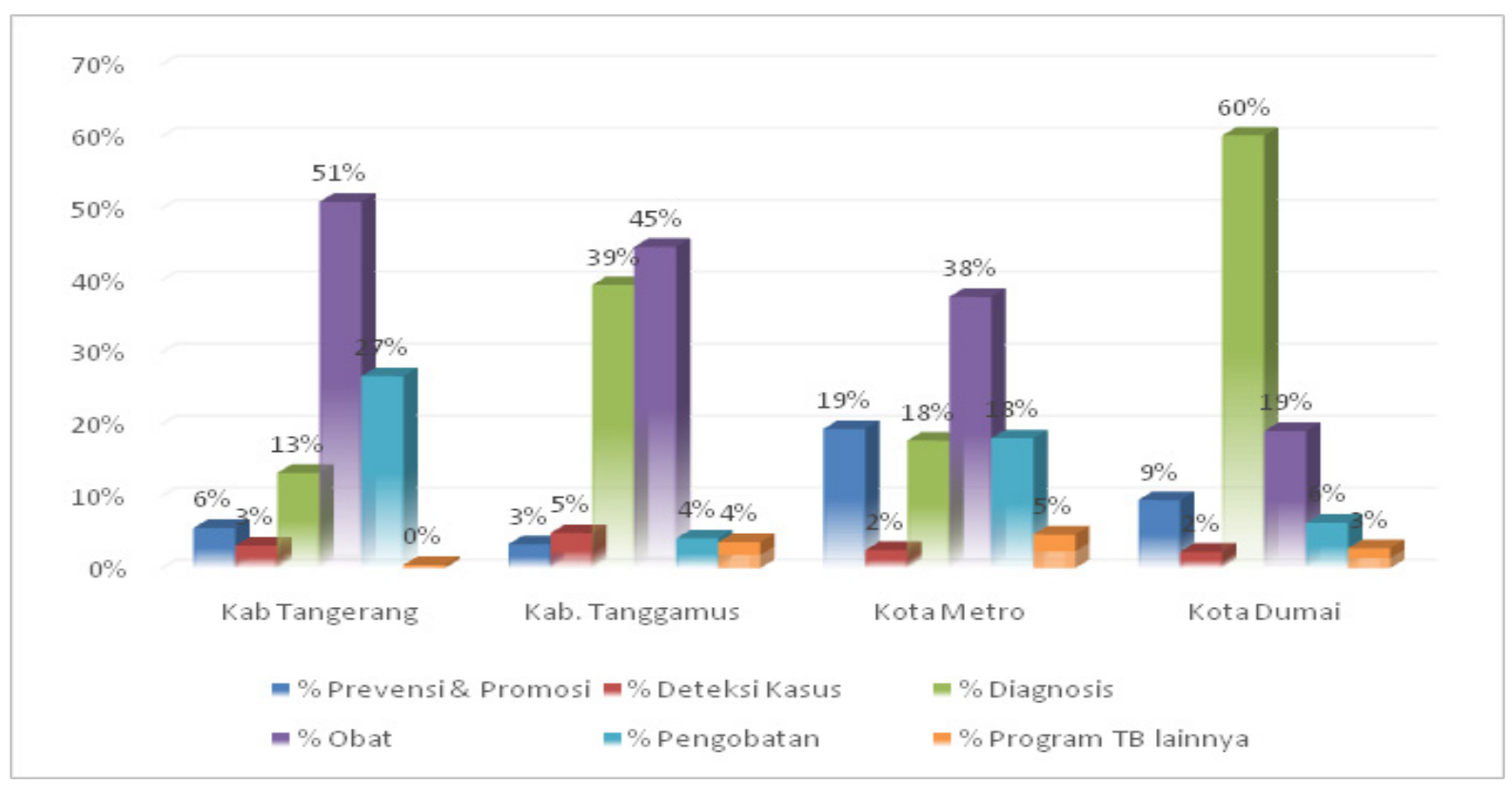

Gambar 2. Alokasi Pembiayaan Program TB di 4 Kabupaten Kota di Sumatera dan Banten Tahun 2016

si Lampung (Kabupaten Tanggamus dan Kota Dumai) adalah yang tertinggi diantara insiden TB di kota lainnya, yaitu masing-masing 383 kasus per 100.000 populasi. Namun, angka notifikasi kasus di kedua wilayah tersebut masih cukup rendah, yaitu hanya 100,45 dan 142,48 per 100.000 penduduk. Hal yang berbeda dapat dilihat di Kota Metro, dengan insiden sebesar 160 per 100.000 penduduk, Case Notification Rate (CNR) yang berhasil dicapai sebesar 126 per 100.000 penduduk. Terkait dengan success rate dan cure rate, Kota Metro memiliki success rate tertinggi, yaitu $89 \%$, sedangkan Kabupaten Tangerang memiliki cure rate $90 \%$, tertinggi diantara kabupaten/kota lainnya (Gambar 1).

Hasil studi menunjukkan bahwa biaya prog- 
Tabel 2. Biaya Program TB

\begin{tabular}{ll}
\hline \multicolumn{1}{c}{ Kabupaten/Kota } & $\begin{array}{c}\text { Biaya Program TB } \\
\text { (Rp) }\end{array}$ \\
\hline Kabupaten Tangerang & Rp. 6.737 .303 .630 \\
Kabupaten Tanggamus & Rp. 590.926 .528 \\
Kota Metro & Rp. 369.747 .926 \\
Kota Dumai & Rp. 1.222 .681 .237 \\
\hline
\end{tabular}

ram TB di Kabupaten Tangerang adalah yang terbesar diantara empat kabupaten/kota lainnya, yaitu sekitar Rp. 6,7 M atau 5 kali lebih besar dari Kota Dumai, 11 kali lebih besar dari Kabupaten Tanggamus dan 18 kali lebih besar dari Kota Metro (Tabel 2). Biaya ini digunakan untuk kegiatan prevensi dan promosi, deteksi kasus, diagnosis, obat, pengobatan, dan program TB lainnya. Diantara kegiatan tersebut, alokasi untuk obat adalah yang paling besar di Kabupaten Tangerang, Tanggamus dan Kota Metro, yaitu sebesar 51\%, 45\% dan 38\%. Biaya obat ini meliputi biaya paket obat TB untuk kategori I Kombinasi Dosis Tetap (KDT), kategori II KDT, kategori anak dan obat untuk TB resisten obat. Sementara itu, di Kota Dumai alokasi biaya tertinggi digunakan untuk biaya diagnosis, sebesar $60 \%$. Biaya diagnosis terdiri dari biaya untuk konsultasi awal, biaya apusan untuk pemeriksaan awal, dan biaya untuk pemeriksaan X-ray. Alokasi paling besar untuk kegiatan prevensi dan promosi hanya sebesar 19\% yang dilakukan oleh Kota Metro. Bahkan di Kabupaten Tanggamus hanya sebesar 3\% (Gambar 2).

Berdasarkan hasil RTD dapat diketahui beberapa permasalahan dan tantangan TB. Permasalahan pertama adalah tatalaksana pengobatan TB yang tidak standar di pelayanan kesehatan non puskesmas. Pada pasien TB anak yang berobat di klinik dokter spesialis anak, saat melakukan rujuk balik ke puskesmas, obat yang diperoleh dari dokter spesialis anak berbeda dengan obat yang diperoleh dari puskesmas. Kondisi tersebut ditemui di Kabupaten Tangerang, Kota Dumai dan Kota Metro. Untuk meminimalisir hal itu, dinas kesehatan dan puskemas menjalin kerjasama dengan dokter spesialis agar menyerahkan upaya pengobatan di puskesmas. Artinya pasien hanya mendapatkan penegakkan diagnosis di klinik, dan pengambilan obat dapat dilakukan di puskesmas. Permasalahan lain yang ditemukan pada kasus TB anak adalah ketersediaan obat TB untuk anak, seperti yang ter- jadi di Kabupaten Tanggamus, ada kasus TB pada anak yang belum mendapatkan obat karena stok obat telah habis. Saat studi ini dilakukan upaya permintaan obat telah dilakukan dan obat telah tersedia. Untuk menghindari terjadinya permasalahan ini kembali, Dinas Kesehatan diharapkan menyediakan buffer stock obat, atau melakukan "peminjaman" obat antar kabupaten.

Permasalahan kedua adalah terkait dengan data yang kurang menggambarkan kondisi yang sebenarnya, seperti yang terjadi di Kabupaten Tangerang. Data jumlah kasus TB yang diterima oleh Wasor di Kabupaten Tangerang masih terbatas pada kasus TB yang berasal dari RSUD Kabupaten Tangerang dan 44 puskesmas. Padahal selain itu, masih ada sekitar 338 klinik swasta dan 12 Rumah Bersalin (RB) yang belum didata terkait dengan kasus TB yang ditangani sehingga besar kemungkinan banyak pasien TB yang berobat di klinik swasta tersebut.

Permasalahan ketiga adalah upaya penemuan kasus baru masih dianggap belum optimal. Dari target nasional 70\% penemuan kasus, Kabupaten Tangerang baru mampu menemukan kasus sebanyak $50 \%$. Salah satu hambatan dalam penemuan kasus adalah terbatasnya SDM/kader untuk menemukan kasus baru. Saat ini, Dinas Kesehatan Kabupaten Tangerang telah memiliki 65 posyandu dan 650 kader, tetapi belum semua kader tersebut bergerak aktif mencari kasus. Beberapa puskesmas mengerahkan kadernya untuk mencari kasus dengan memberikan insentif pencarian kasus yang berasal dari dari BOK. Penggunaan dana BOK untuk pencarian kasus ini merupakan kebijakan internal puskesmas dan belum semua puskesmas di Kabupaten Tangerang memiliki kebijakan serupa. Penyebab lainnya adalah penemuan kasus hanya berdasarkan pada active case finding di masyarakat. Namun, upaya ini di Kota Metro agak terhambat oleh rendahnya intensif yang diterima oleh kader pencari kasus. Bahkan di suatu wilayah diketahui ada satu kasus BTA+ tetapi belum mendapatkan respon dari kader karena kader tidak memiliki kendaraan untuk menjangkau lokasi kasus.

Permasalahan keempat adalah rendahnya penemuan kasus pada populasi rentan. Kelompok populasi rentan yang menjadi pembahasan pada saat RTD adalah populasi yang berada di 
pesantren dan kelompok berisiko tinggi HIV. Jangkauan pencarian kasus oleh puskesmas pada populasi rentan di Kabupaten Tangerang masih terbatas pada populasi di pesantren, melalui Unit Kesehatan Pesantren (UKP). Namun, saat kasus ditemukan di kelompok tersebut, tindak lanjut pengobatan dan lainnya sulit untuk dilakukan karena santri yang terkena biasanya akan pulang ke tempat tinggal asalnya. Kondisi ini dipersulit oleh banyaknya pesantren yang ada di Kabupaten Tangerang yang mencapai sekitar 632 pesantren. Pada dasarnya ada dua jenis pesantren, yaitu pesantren salafiah, yang merupakan pesantren tradisional dan tidak memiliki unit kesehatan, dan pesantren modern, yang memiliki unit kesehatan. Sehingga untuk pencarian kasus pada populasi sebanyak itu perlu melibatkan LSM. Sementara itu di Kota Dumai upaya pencarian kasus TB pada populasi berisiko tinggi seperti populasi penderita HIV dan populasi risiko tinggi HIV, selama ini masih terbatas pada pemeriksaan BTA pada kasus HIV. Dinas kesehatan belum melakukan pemeriksaan TB pada kelompok risiko tinggi HIV seperti kelompok waria, kelompok Lelaki Suka Lelaki (LSL), kelompok penasun dan kelompok Wanita Pekerja Seks (WPS). Selama ini yang banyak bergerak pada kelompok tersebut adalah LSM. Namun, kerjasama dengan kelompok masyarakat dan LSM masih sangat terbatas. Hingga saat ini Dinas Kesehatan Kota Dumai baru melakukan kerjasama dengan Aisyiah dan LSM HIV.

Permasalahan kelima adalah keterbatasan SDM program TB. Untuk itu, perlu dilakukan kerjasama dengan LSM dan Organisasi Profesi untuk promosi dan pencarian kasus TB. Hingga saat ini unsur masyarakat yang aktif dalam pencarian kasus TB di keempat kabupaten/kota adalah Aisyiah, sedangkan peran serta kader kesehatan baru sebatas pada upaya promosi TB. Sementara itu organisasi profesi masih melakukan promosi TB secara terpisah dan belum terintegrasi dengan organisasi profesi lainnya ataupun dengan instansi terkait. Oleh karena itu, Dinas Kesehatan berencana akan mengkoordinir Organisasi Profesi, seperti IBI, PPNI, IDI dan IAKMI, untuk secara aktif terlibat dalam promosi TB.

Permasalahan keenam adalah kontribusi Corporate Social Responsibility (CSR) masih dirasa sangat rendah. Keempat kabupaten/kota memiliki banyak perusahaan dengan potensi CSR yang cukup tinggi. Pemanfaatan dana CSR tersebut belum menyentuh program kesehatan. Semua dana CSR digunakan untuk program yang memiliki dampak langsung, seperti memberian modal usaha, pembangunan "fisik". Untuk bisa menjembatani dinas kesehatan dengan CSR perusahaan harus melalui dinas sosial. Di Kota Metro, upaya pendekatan dengan CSR telah dilakukan oleh Sosial Budaya (Sosbud) Bapeda Kota Metro melalui pertemuan rutin bulanan dengan CSR industri/perusahaan.

Sejalan dengan hasil perhitungan beban biaya TB, keempat kabupaten/kota menghadapi permasalahan yang sama, yaitu kurangnya upaya promotif dan preventif, yang merupakan permasalahan nomor tujuh. Hal ini disebabkan oleh tren penurunan anggaran TB yang dialokasikan dari APBD. Sebagai contoh di Dinas Kesehatan Kabupaten Tanggamus pada tahun 2016 telah mengajukan anggaran program TB sebesar Rp. 150 juta, tetapihanya $20 \%$ dari dana tersebut yang disetujui (Rp. 30 juta). Kekurangan dana program tersebut kemudian dicover oleh dana BOK. Pemanfaatan dana BOK untuk program TB juga dilakukan di Kota Metro. Keterbatasan anggaran menyebabkan tidak adanya kegiatan pelacakan kasus di Kota Dumai. Dampak selanjutnya adalah pengobatan TB tidak sepenuhnya gratis. Pasien masih harus mengeluarkan biaya untuk pemeriksaan rontgen. Biaya rontgen ini dirasa masih cukup tinggi terlebih bagi pasien yang berasal dari sosial ekonomi rendah. Perlu adanya kerjasama lintas sektor (dengan dinas sosial) untuk dapat memenuhi anggaran tersebut dengan memanfaatkan dana sosial dan kerjasama dengan Dinas Pemberdayaan Masyarakat Desa untuk memanfaatkan Dana Desa. Keterbatasan dana di Kabupaten Tanggamus menyebabkan operasionalisasi alat Tes Cepat Molekuler (TCM) terhambat karena terkendala dengan kesiapan ruangan. Untuk dapat mengoperasionalisasikan alat tersebut, RSUD perlu melakukan renovasi ruangan agar sesuai dengan kelayakan ruangan untuk alat TCM. Ke depannya bersamaan dengan adanya bantuan alat TCM perlu dipertimbangkan juga untuk meminta komitmen dari provinsi agar dapat membantu penyiapan ruangan.

Permasalahan kedelapan adalah adanya stigma masyarakat tentang TB. Masalah ini dira- 
sa cukup unik karena dari empat kabupaten/kota yang diamati hanya terjadi di Kota Metro. Hal ini menjadi isu di Puskesmas Girimulyo, Kota Metro. Penyakit TB merupakan penyakit terbanyak ketiga di puskesmas tersebut. Walaupun kasus TB sudah cukup banyak, tetapi masih ada stigma di masyarakat bahwa penyakit TB adalah penyakit yang memalukan sehingga banyak dari penderita TB yang dikucilkan. Hal ini menyebabkan rendahnya pencarian pengobatan oleh masyarakat yang mengalami gejala-gejala TB.

Permasalahan kesembilan adalah kesulitan dalam monitoring kasus dan survei kontak, seperti yang dialami oleh Kota Metro. Kota Metro merupakan wilayah urban yang di dalamnya banyak sekali masyarakat pendatang dari wilayah sekitar, seperti dari Kabupaten Lampung Timur dan Lampung Tengah. Kasus TB yang diderita oleh para pendatang biasanya terdiagnosis di Kota Metro, tetapi saat proses pengobatan pasien tersebut biasanya kembali ke daerah asal sehingga tidak dapat diketahui status pasien TB tersebut, seperti yang terjadi pada satu orang kasus TB-MDR, setelah pasien tersebut didiagnosis TB-MDR, pengobatan dilakukan di luar Kota Metro. Selain itu, hal ini juga menyebabkan petugas kesulitan melakukan survei kontak.

Masalah kesepuluh adalah banyaknya pasien TB yang berasal dari kelompok ekonomi rendah dan kelompok pekerja. Untuk penanganan pasien TB pada kelompok ekonomi rendah, penggunaan dana bantuan sosial untuk mendukung penanganan TB pada pasien kurang mampu (misalnya memberikan makanan tambahan) dapat diarahkan pada pemanfaatan dana desa oleh Pekon (ketua kampung) dari alokasi sekitar 30\% untuk pemberdayaan masyarakat. Dana ini juga dapat dimanfaatkan untuk transportasi pasien saat memerlukan ambulans menuju ke pelayanan kesehatan.

\section{PEMBAHASAN}

Dari empat wilayah studi, program pengendalian TB di tiga wilayah masih belum optimal. Hal ini ditunjukkan dengan tidak tercapainya target CNR. Biaya program yang diperlukan untuk pengendalian TB di setiap wilayah sangat variatif, yaitu sekitar Rp. 369 juta hingga Rp. 6,7 miliar. Alokasi penggunaan dana pengendalian TB di tiga wilayah yang belum mencapai target CNR, pal- ing banyak digunakan untuk pemberian obat, sedangkan pada wilayah yang telah mencapai target CNR, alokasi terbesar digunakan untuk diagnosis. Permasahan terkait dengan kepatuhan terhadap prosedur tatalaksana kasus, kekurangan SDM, belum adanya kerjasama lintas sektor, keterbatasan anggaran, dan stigma negatif tentang TB merupakan hal yang menjadi kendala dalam pengendalian TB di empat wilayah ini.

Studi ini menggunakan instrumen TB costing tools untuk melakukan analisis biaya program. Sayangnya saat pengisian TB costing tools ada beberapa asumsi yang tidak diperoleh dari rujukan yang akurat, seperti informasi mengenai biaya persentase promosi untuk kegiatan TB hanya didasarkan pada perkiraan karena pada kenyataannya kegiatan promosi TB dilakukan secara terintegrasi dengan promosi kesehatan lainnya. Asumsi lainnya yang kurang lengkap adalah terkait dengan asumsi pada pasien yang tidak mendapat pengobatan karena kami tidak dapat menggali informasi dari pasien yang tidak berobat. Semua pasien yang diwawancara adalah pasien yang berobat.

Angka penemuan kasus TB di Kota Metro, Kabupaten Tangerang dan Kabupaten Tanggamus pada tahun 2016 masih cukup rendah bila dibandingkan dengan target penemuan kasus pada masing-masing wilayah tahun 2017. Rendahnya temuan kasus menunjukkan bahwa kinerja program masih perlu ditingkatkan. Shargie, Morkve dan Lindtjorn ${ }^{8}$ menyebutkan bahwa keberhasilan program TB ditunjukkan dengan banyaknya kasus yang terdeteksi, kecepatan kasus tersebut teridentifikasi dan berapa banyak pasien yang mendapatkan pengobatan lengkap.

Kondisi ini berbanding terbalik dengan situasi TB di Kota Dumai yang berhasil mencapai CNR sebesar 126 kasus per 100.000 penduduk pada tahun 2016, dan angka ini melebihi target performance CNR Provinsi Riau 123 kasus per 100.000 penduduk. Tingginya angka temuan kasus ini merupakan suatu hal yang patut diapresiasi. Ditengah keterbatasan anggaran untuk program TB, temuan kasus TB di Kota Dumai tetap dapat memenuhi target provinsi. Tingginya temuan kasus dan CNR di Kota Dumai salah satunya disebabkan juga karena Kota Dumai merupakan wilayah urban. Kondisi wilayah urban ini akan terkait dengan kondisi sosial ekonomi rendah, ${ }^{9,10}$ ke- 
padatan penduduk yang tinggi $i^{11}$ dan tingginya angka prevalensi HIV-AIDS. ${ }^{12}$ Studi yang dilakukan di Ethiopia Selatan dilaporkan tingginya kejadian TB dengan koinfeksi HIV (25-30\%) pada wilayah urban. ${ }^{13}$ Kota Dumai adalah kota jasa dan industri dan hal ini memicu peningkatan prevalensi HIV. Berdasarkan profil kesehatan Kota Dumai tahun 2015 diketahui bahwa setiap tahun kasus HIV dan AIDS dilaporkan terjadi di Kota Dumai. Secara kumulatif kasus HIV terdapat sebanyak 305 kasus dan 186 kasus AIDS.

Untuk dapat meningkatkan temuan kasus, salah satu upaya yang dapat dilakukan adalah dengan public-private mixed. Systematic review yang dilakukan pada 41 program pengendalian TB dengan public-private mixed menunjukkan terjadi peningkatan temuan kasus yang cukup besar, yaitu sekitar 8\%-11\% di Bangladesh dan Kerala, India, hingga bahkan mencapai lebih dari $70 \%$ seperti yang terjadi di Hyderabad, India dan Yogyakarta, Indonesia. ${ }^{14}$

Upaya penemuan kasus TB dipengaruhi oleh beberapa faktor, yaitu faktor perilaku individu dalam mencari pengobatan, akses terhadap pelayanan kesehatan, dan kapasitas pemeriksaan laboratorium. ${ }^{8}$ Terkait dengan akses layanan kesehatan dan kapasitas laboratorium, hasil round table discussion di Kota Metro menunjukkan bahwa tidak ada permasalahan akses pelayanan kesehatan di Kota Metro. Begitu juga dengan kapasitas pemeriksaan laboratorium fasilitas dan SDM sudah tersedia dengan baik. Yang menjadi permasalahan di Kota Metro adalah adanya stigma negatif tentang penyakit TB yang menyebabkan penderita merasa malu dan enggan untuk melakukan pemeriksaan dan pengobatan ke fasilitas kesehatan. Hal ini sesuai dengan studi yang dilakukan di India bahwa sebanyak $60 \%$ pasien menyembunyikan penyakitnya karena stigma negatif ini, dan kondisi ini lebih banyak ditemui pada kelompok masyarakat ekonomi rendah dibandingkan pada kelompok ekonomi menengah dan tinggi. ${ }^{15} \mathrm{Se}-$ mentara itu, di Kabupaten Tanggamus dipengaruhi oleh health seeking behavior masyarakat dalam pengobatan TB masih cukup rendah. Masyarakat masih meremehkan gejala batuk walaupun sudah berlangsung selama lebih dari dua minggu. Hal ini sejalan dengan studi yang dilakukan oleh Oberoi ${ }^{16}$ bahwa tanda dan gejala penyakit secara bersa- maan dengan karakteristik pasien, karakteristik pelayanan kesehatan, faktor sosial dan demografi, biaya, jaringan sosial memengaruhi perilaku pencarian pengobatan.

Upaya peningkatan penemuan kasus di daerah juga sedikit terhambat dengan kurangnya SDM untuk penemuan kasus. Oleh karena itu, perlu melibatkan masyarakat (kader) untuk secara aktif melakukan pencarian kasus, salah satunya dengan melibatkan LSM Aisyiah dalam menemukan kasus. Pelibatan masyarakat dalam pencarian kasus berdasarkan studi yang dilakukan di Kamboja terbukti efektif untuk meningkatkan temuan kasus, dan dari aspek biaya juga cukup cost effective. ${ }^{17}$ Temuan ini juga didukung oleh hasil studi Syafar ${ }^{18}$ di Kota Makassar bahwa keterlibatan SSR Muslimat NU selain mampu meningkatkan penemuan kasus, tetapi juga peningkatan kesembuhan pasien TB. LSM menjadi mitra pembentukan kelompok masyarakat peduli TB dan pemerintah mendaklanjuti temuan kasus dengan penatalaksaan pengobatan TB.

Salah satu penyebab rendahnya temuan kasus di kabupaten/kota yang diamati adalah keterbatasan anggaran. Peningkatan anggaran untuk program TB sekarang ini mengalami sedikit hambatan karena di keempat wilayah tersebut belum ada payung hukum. Padahal jika merujuk pada Peraturan Menteri Kesehatan No 67 Tahun 2016 tentang Penanggulangan Tuberkulosis di pasal 20 disebutkan bahwa Pemerintah Pusat dan Pemerintah Daerah wajib menjamin ketersediaan anggaran Penanggulangan TB. Kesadaran terhadap pentingnya kebijakan program TB di semua wilayah sudah mulai muncul. Dengan jumlah kasus TB yang terus meningkat, tentu saja keberadaan payung hukum program TB menjadi sangat penting. Sebagai langkah awal, payung hukum yang akan dibuat adalah Peraturan Bupati. Hal ini dinilai cukup tepat untuk membuat payung hukum dalam kurun waktu yang relatif singkat. Hal ini sudah dilakukan oleh Kabupaten Siak. Kabupaten Siak telah memiliki Peraturan Bupati No 46 Tahun 2016 tentang Pemberantasan dan Eliminasi Penyakit Tuberkulosis. Dengan adanya Peraturan Bupati ini, maka pemerintah daerah wajib menganggarkan biaya pemberantasan dan eliminasi TB ke dalam APBD. Selain itu, kerjasama lintas sektor pun dapat lebih mudah dilakukan jika suatu program sudah berlan- 
daskan pada payung hukum yang jelas.

Tentunya seiring dengan upaya penyusunan payung hukum (perda) TB ini, perlu juga diiringi dengan aktivitas lainnya agar saatnya nanti Perda TB ini dapat terimplementasikan dengan baik. Merujuk pada teori Donald S. Van Meter dan Carl E. Van Horn, ${ }^{19}$ bahwa implementasi kebijakan dipengaruhi oleh enam variabel, yaitu (1) standar dan sasaran kebijakan; (2) sumberdaya; (3) komunikasi antar organisasi dan penguatan aktivitas; (4) karakteristik agen pelaksana; (5) disposisi implementor; (6) kondisi sosial, ekonomi dan politik.

Menilik pada variabel tentang standar dan sasaran kebijakan, untuk pengendalian TB sasaran kebijakan telah jelas ditetapkan untuk tingkat pusat, provinsi dan kabupaten. Sehingga Dinas Kesehatan kabupaten/kota tinggal mengikuti. Terkait dengan variabel sumber daya, hasil studi menunjukkan bahwa sumber daya yang paling diperlukan dalam pengendalian TB adalah SDM untuk pencarian kasus. Para kader perlu mendapatkan insentif untuk lebih aktif mencari kasus. Variabel ketiga adalah komunikasi organisasi dan penguatan aktivitas. Hal ini dapat terealisasikan dengan melakukan kerjasama lintas sektor. Sebagai contoh Dinas Kesehatan perlu melakukan kerjasama dengan Dinas Tenaga Kerja untuk penguatan Unit Kesehatan Kerja (UKK) di perusahaan. Kerjasama dengan Dinas Sosial pun perlu dilakukan untuk menjembatani Dinas Kesehatan dengan CSR perusahaan agar dapat mendukung program TB yang dilakukan oleh Dinas Kesehatan.

Terkait dengan variabel karakteristik agen pelaksana, dalam suatu implementasi kebijakan agar mencapai keberhasilan maksimal harus diidentifikasikan dan diketahui karakteristik agen pelaksana yang mencakup struktur birokrasi, norma-norma, dan pola-pola hubungan yang terjadi dalam birokrasi, semua itu akan mempengaruhi implementasi suatu program kebijakan yang telah ditentukan. Variabel selanjutnya adalah disposisi implementor. Dalam implementasi kebijakan sikap atau disposisi implementor ini dibedakan menjadi tiga hal, yaitu; (a) respons implementor terhadap kebijakan, yang terkait dengan kemauan implementor untuk melaksanakan kebijakan publik; (b) kondisi, yakni pemahaman terhadap kebijakan yang telah ditetapkan; dan (c) intens disposisi implementor, yakni preferensi nilai yang dimiliki tersebut.

Variabel terakhir adalah kondisi lingkungan sosial, politik dan ekonomi. Variabel ini mencakup sumberdaya ekonomi lingkungan yang dapat mendukung keberhasilan implementasi kebijakan, sejauh mana kelompok-kelompok kepentingan memberikan dukungan bagi implementasi kebijakan; karakteristik para partisipan, yakni mendukung atau menolak; tentang sifat opini publik yang ada di lingkungan dan apakah elite politik mendukung implementasi kebijakan.

Terkait dengan pembiayaan program, secara umum diketahui bahwa alokasi program pengendalian TB paling banyak digunakan untuk biaya obat (38\%-51\%). Hasil ini selaras dengan studi yang dilakukan di DKI Jakarta bahwa alokasi biaya terbesar untuk setiap pasien TB adalah untuk biaya obat $(55 \%) .{ }^{20}$ Walaupun demikian, kebijakan nasional pemerintah Indonesia adalah bahwa setiap obat untuk kasus TB disiapkan oleh pemerintah pusat melalui APBN, sehingga alokasi dana obat ini pada faktanya tidak membebani pemerintah daerah. ${ }^{4}$ Di Kota Dumai alokasi anggaran tertinggi adalah untuk diagnosis, yang mencapai $61 \%$, sedangkan untuk obat hanya sebesar $19 \%$. Data tersebut mengindikasikan banyaknya suspek TB yang diperiksa (3.686 suspek), tetapi hanya sekitar $8 \%$ yang perlu diobati (BTA positif) pada tahun 2016. Kondisi ini berbeda dengan kondisi di Kabupaten Tangerang yang mana ada sebanyak $12,76 \%$ suspek yang terkonfirmasi BTA positif dan Kabupaten Tanggamus sebanyak 20,94\%.

Keterbatasan dalam penulisan analisis situasi berasal dari ketidaklengkapan data sekunder, penggunaan asumsi dan proses round table discussion. Komponen penggunaan data sekunder dalam analisis situasi ini sangatlah besar, yaitu berasal dari data Kabupaten Dalam Angka, Profil Kesehatan dan Data SITT. Dari ketiga sumber tersebut peneliti memiliki keterbatasan untuk mendapatkan data Profil Kesehatan Kabupaten Tangerang tahun 2014 dan tahun 2016. Profil Kesehatan pada tahun tersebut tidak tersedia sehingga peneliti hanya menggunakan sumber data dari Profil Kesehatan tahun 2015 saja. Tentunya dengan kondisi ini maka gambaran situasi kesehatan tidak dapat secara komprehensif menggambarkan kondisi 3 tahun terakhir (2014-2016). 


\section{KESIMPULAN DAN SARAN}

Dari hasil studi dapat disimpulkan bahwa penemuan kasus TB di tiga kabupaten/kota belum dilakukan secara optimal, hal ini terlihat dari rendahnya capaian CNR (100,00-142,48 per 100.000 penduduk). Kota Dumai merupakan satu-satunya daerah dengan CNR yang melebih target (126 per 100.000 penduduk). Success rate TB berkisar antara $52 \%-90 \%$, sedangkan cure rate berkisar antara 52\%-88\%. Sementara itu biaya program TB berkisar antara Rp. 369.747.926,sampai Rp. 6.737.303.630,-. Pelaksanaan program TB di setiap wilayah terkendala oleh beberapa faktor, yaitu tatalaksana kasus tidak standar, underestimated data, temuan kasus baru masih kurang, terbatasnya SDM program TB, kontribusi CSR sangat rendah, kurangnya upaya promotif dan preventif tentang TB, stigma buruk TB, kesulitan monitoring dan evaluasi kasus serta survei kontak, dan permasalahan pasien dari kelompok miskin dan kelompok pekerja. Kompleksitas permasalahan pengendalian TB memerlukan penyelesaian yang komprehensif, dan studi ini merekomendasikan kepada para pimpinan daerah untuk membuat suatu kebijakan tingkat kabupaten/kota (Peraturan Daerah atau Peraturan Bupati/Walikota). Kebijakan ini mampu memberikan kepastian anggaran pengendalian TB dengan mengalokasikan APBD untuk program TB. Dengan adanya kebijakan ini kerjasama lintas sektor pun dapat lebih mudah dilakukan. Rekomendasi lainnya adalah dinas kesehatan diharapkan mampu menjaga konsistensi pengisian data SITT dan profil kesehatan mengingat kedua data ini menjadi rujukan utama untuk mengetahui gambaran kesehatan, khususnya penyakit $\mathrm{TB}$, di masing-masing wilayah.

\section{UCAPAN TERIMA KASIH}

Penelitian didanai oleh The Global Fund melalui PR Aisyiah. Peneliti mengucapkan terima kasih yang sebesar-besarnya kepada SR Provinsi dan SSR kabupaten/kota atas pendampingan selama pengumpulan data. Rasa terima kasih yang tak terhingga kami ucapkan juga kepada Dinas Kesehatan Kabupaten Tangerang, Dinas Kesehatan Kabupaten Tanggamus, Dinas Kesehatan Kota Metro dan Dinas Kesehatan Kota Dumai, serta para wasor atas kerjasama selama pengumpulan data.

\section{DAFTAR PUSTAKA}

1. WHO. Global Tuberculosis Report 2017. Jenewa: WHO; 2017.

2. Pusdatin. Tuberkulosis: Temukan Obati Sampai Sembuh. Jakarta: 2016.

3. Collins D, Hafidz F, Mustikawati D. The Economic Burden of Tuberculosis in Indonesia. The International Journal of Tuberculosis and Lung Disease. 2017;21(9):1041-8.

4. Setiawan E, Sucahya PK, Thabrany H, Komaryani K. A Comparative Budget Requirements for TB Program Based on Minimum Standard of Services (SPM) and Budget Realization: an Exit Strategy Before Termination of GF ATM. Jurnal Ekonomi Kesehatan Indonesia. 2016;1(1).

5. Subdit TB. Pembiayaan AIDS, TB dan Malaria (ATM) Menyongsong BPJS 2014. Warta Tuberkulosis Indonesia. 2013;23(April):1.

6. Kementerian Kesehatan RI. Buku Rencana Aksi Nasional Kolaborasi TBHIV 2015-2019. Jakarta: Kementerian Kesehatan 2015.

7. USAID. TB Care I Costing Tools. 2018 [cited 2018]. Available from: https://www.challengetb.org/publications/tools/costing/TB CARE_I_Costing_Tools.pdf.

8. Shargie EB, Mørkve O, Lindtjørn B. Tuberculosis Case-Finding through a Village Outreach Programme in a Rural Setting in Southern Ethiopia: Community Randomized Trial. Bulletin of the World Health Organization. 2006;84:112-9.

9. Mason PH, Degeling C, Denholm J. Sociocultural Dimensions of Tuberculosis: an Overview of Key Concepts. The International Journal of Tuberculosis and Lung Disease. 2015;19(10):1135-43.

10. Andrews JR, Basu S, Dowdy DW, Murray MB. The Epidemiological Advantage of Preferential Targeting of Tuberculosis Control at the Poor. The International Journal of Tuberculosis and Lung Disease. 2015;19(4):375-80.

11. Boccia D, Hargreaves J, De Stavola BL, Fielding $\mathrm{K}$, Schaap A, Godfrey-Faussett $\mathrm{P}$, et al. The Association Between Household Socioeconomic Position and Prevalent Tuberculosis in Zambia: a Case-Control Study. PloS one. 2011;6(6):e20824.

12. Abebe Y, Schaap A, Mamo G, Negussie A, 
Darimo B, Wolday D. HIV Prevalence in 72 000 Urban and Rural Male Army Recruits, Ethiopia. Aids. 2003;17(12):1835-40.

13. Ahmed Yassin M, Takele L, Gebresenbet S, Girma E, Lera M, Lendebo E, et al. HIV and Tuberculosis Coinfection in the Southern Region of Ethiopia: a Prospective Epidemiological study. Scandinavian Journal of Infectious diseases. 2004;36(9):670-3.

14. Lei X, Liu Q, Escobar E, Philogene J, Zhu H, Wang Y, et al. Public 2013; Private Mix for Tuberculosis Care and Control: a Systematic Review. International Journal of Infectious Diseases. 2015;34:20-32.

15. Dhingra V, Khan S. A Sociological Study on Stigma among TB Patients in Delhi. Indian Journal of Tuberculosis. 2010;57(1).

16. Oberoi S, Chaudhary N, Patnaik S, Singh A. Understanding Health Seeking Behavior.
Journal of Family Medicine and Primary Care. 2016;5(2):463.

17. Eang MT, Satha P, Yadav RP, Morishita F, Nishikiori N, van-Maaren $P$, et al. Early Detection of Tuberculosis through Community-Based Active Case Finding in Cambodia. BMC Public Health. 2012;12(1):469.

18. Syafar M, Abna NJ. Kemitraan Pemerintah dengan Muslimat NU (NGO) dalam Pengendalian Tuberkulosis Paru. Media Kesehatan Masyarakat Indonesia. 2017;13(3):281-8.

19. Van Meter DS, Van Horn CE. The Policy Implementation Process: A Conceptual Framework. Administration \& Society. 1975;6(4):445-88.

20. Sari ID, Herman MJ, Susyanty AL, Su'udi A. Analisis Biaya Tuberkulosis Paru Kategori Satu Pasien Dewasa di Rumah Sakit di DKI Jakarta. Jurnal Kefarmasian Indonesia. 2018;8(1):44-54. 